\title{
The Effects of Social Skills Training vs. Psychoeducation on Negative Attitudes of Mothers of Persons with Schizophrenia: A Pilot Study
}

\author{
Chulkwon Kim ${ }^{1}$ and Kim T. Mueser ${ }^{2} \bowtie$ \\ ${ }^{1}$ Department of Psychiatry, College of Medicine, Dong-A University, Busan, Korea \\ 2Departments of Psychiatry and of Community and Family Medicine Dartmouth Medical School, Concord, USA
}

\begin{abstract}
Objective We compared the effects of two brief psychoeducation programs and social skills training on the negative attitudes of mothers with a son who has schizophrenia.

Methods 15 mothers with strong negative feelings towards a sons with schizophrenia were assigned by convenience to participate in one of three brief (5 session) group programs at an outpatient clinic: lecture-based psychoeducation, video-based psychoeducation, or social skills training. Assessments using the Patient Rejection Scale were conducted with the mothers at post-treatment, and 3-, 6-, and 9-months later.

Results Mothers in the three groups demonstrated significantly different patterns of changes in their negative attitudes following treatment. Whereas the mothers who received the two psychoeducation interventions showed reductions in rejecting attitudes immediately following the program, their scores gradually increased at the subsequent follow-up assessments. In contrast, the mothers in the social skills training group showed reductions in negative attitudes that were sustained across all of the follow-up assessments.

Conclusion Brief social skills training may be more effective than psychoeducation in reducing negative attitudes of parents who have an offspring with schizophrenia.

Psychiatry Investig 2011;8:107-112
\end{abstract}

Key Words Schizophrenia, Family burden, Psychoeducation, Social skills training, Negative attitudes, Patient rejection.

\section{INTRODUCTION}

Providing care to a loved one with schizophrenia can be a challenging experience, both with respect to the time, expense, and loss of other opportunities associated with caregiving, or objective burden, and emotionally, as relatives must contend with feelings of worry, anxiety, guilt, frustration, and anger in their attempts to cope with a strange and unpredictable illness, or subjective burden. ${ }^{1,2}$ Although many relatives report gratifications associated with caring for a close persons with severe mental illness, ${ }^{3}$ strained relationships are common, as shown

Received: October 8, 2010 Revised: February 15, 2011

Accepted: March 14, 2011 Available online: April 14, 2011

$\triangle$ Correspondence: Kim T. Mueser, PhD

Departments of Psychiatry and of Community and Family Medicine Dartmouth

Medical School, Dartmouth Psychiatric Research Center Main Building, 105

Pleasant St. Concord, NH 03301, USA

Tel: +1-603-271-5747, Fax: +1-603-271-5265

E-mail: kim.t.mueser@dartmouth.edu

(c) This is an Open Access article distributed under the terms of the Creative Commons Attribution Non-Commercial License (http://creativecommons.org/licenses/by$\mathrm{nc} / 3.0$ ) which permits unrestricted non-commercial use, distribution, and reproduction in any medium, provided the original work is properly cited. in research on expressed emotion in families. ${ }^{4} \mathrm{~A}$ major factor contributing to distress in caregivers is the severity and disruptiveness of the relative's symptoms and behaviors, such as unpredictable shifts in mood and thinking, bizarre and frightening or embarrassing behavior, failure to follow through on treatment, lack of initiative and involvement in family life, and substance abuse. ${ }^{5,6}$

Bolstering the coping skills of caregivers for managing disruptive, symptomatic behavior in a loved one has been recommended as one approach to reducing relative distress. ${ }^{6,7} \mathrm{Im}$ proved coping skills are a common goal of intermediate or long-term multi-family groups, which usually combine psychoeducation with family support and problem solving delivered over at least several months, if not longer. ${ }^{8-12}$ Furthermore, some long-term single family interventions for schizophrenia (e.g., nine months or more) combine psychoeducation with skills training approaches in order to improve the coping of family members. ${ }^{13-15}$

However, shorter-term interventions (e.g., less than 3 months) for family members tend to emphasize psychoeducation 
about mental illness, with little or no attention to enhancing coping skills. ${ }^{16-19}$

To our knowledge, no short-term family intervention programs for schizophrenia have attempted to reduce caregiver distress by focusing mainly on skills training rather than providing psychoeducation about the illness. Social skills training techniques have significant potential for reducing caregiver distress as it involves the systematic teaching of new interpersonal skills that can be used immediately by participants to improve their interactions with others, ${ }^{20,21}$ including family members. This may enable caregivers to begin experiencing the positive effects of more effective communication skills after only a few sessions of training, with the improved communication maintained over the long-term due to its naturally reinforcing effects on reduced interpersonal distress.

The present pilot study was conducted to evaluate the feasibility and potential clinical benefits of providing short-term social skills training to family caregivers aimed at improving their skills for interacting with an offspring with schizophrenia. As teaching family members information about schizophrenia and its treatment is considered the most standard approach to short-term family psychoeducation, ${ }^{7,22,23}$ we chose to compare the skills training intervention to two didactic approaches to group family psychoeducation: in-person teaching and video-based teaching. We hypothesized that short-term social skills training would lead to more sustained reductions in caregiver distress compared to the two short-term family psychoeducation approaches.

\section{METHODS}

The study took place at an outpatient mental health treatment program affiliated with Dong-A university hospital in Korea. All research methods were approved by the local university Institutional Review Board.

\section{Participants}

The subjects were mothers who had a son with schizophrenia receiving outpatient psychiatric treatment at Dong-A university hospital in Korea, and who reported strong, distressing feelings about their relationship with their son. In order to identify mothers with high levels of distress related to their relationship with their son, mothers of sons with schizophrenia living at home completed a revised version of the Patient Rejection Scale. ${ }^{24}$ This scale includes 11 items (four are reversed scored), each one rated on a three-point scale, corresponding to: $1=$ never, $2=$ sometimes, and $3=$ often, with high scores reflecting more negative, rejecting attitudes towards the family member with mental illness. In order to increase the potential sensitivity of this scale to intervention, the three-point rating scale was changed to a five-point scale, corresponding to: $1=$ never, $2=$ seldom, $3=$ sometimes, $4=$ often, and $5=$ constantly. Mothers who scored a 3 or higher on all 11 items (after reversing scores on the four items) were eligible to participate in the study. See Measures section for more information about the Patient Rejection Scale.

Eligible mothers were provided an explanation about the research, which was described as a study intended to compare different approaches to helping family members cope with a close relative who has schizophrenia. After the nature of the interventions were described, and the assessment procedures were completed, interested mothers provided written informed consent to participate in the research. They were then assigned to the next available group they could attend. Different times were established for the family intervention programs, and thus each mother were assigned to the group that was scheduled at the time that could be most readily accommodated into her schedule.

A total of 15 mothers participated in the study. All of the mothers were in their 50s, had graduated high school, and had sons who were in their 20 s who had also graduated high sc-

Table 1. Means and standard deviations of baseline characteristics of study participants in three treatment groups: live psychoeducation $(\mathrm{N}=5)$, video psychoeducation $(\mathrm{N}=5)$, or social skills training $(\mathrm{N}=5)$

\begin{tabular}{lccc}
\hline & Live psychoeducation & Video psychoeducation & Social skills training \\
\hline Mother's age & $52.80(5.89)$ & $56.00(1.41)$ & $53.80(2.39)$ \\
Mother's years of education & $12.80(1.79)$ & $12.80(1.79)$ & $13.60(2.19)$ \\
Patient's age & $26.40(1.67)$ & $27.60(1.14)$ & $26.00(1.87)$ \\
Patient's years of education & $14.60(2.41)$ & $15.60(0.89)$ & $16.20(1.48)$ \\
Duration of patient's illness & $4.60(1.52)$ & $5.40(2.51)$ & $5.20(1.92)$ \\
Patient's PANSS total score & $74.20(3.42)$ & $66.40(8.36)$ & $70.40(4.16)$ \\
Patient's PANSS positive subscale & $22.00(2.45)$ & $23.20(3.03)$ & $24.80(3.56)$ \\
Patient's PANSS negative subscale & $21.00(4.58)$ & $23.60(2.07)$ & $22.40(4.39)$ \\
Patient's PANSS general subscale & $31.20(4.97)$ & $30.40(12.34)$ & $37.60(2.70)$ \\
Mother's total score on patient rejection scale & $36.00(2.00)$ & & $23.20(4.32)$ \\
\hline
\end{tabular}


hool. The baseline demographic and clinical characteristics of the study participants in each of the three treatment groups (see below) are summarized in Table 1. One-way analyses of variance (ANOVAs) were performed to evaluate whether there were any significant differences between the groups. None of these ANOVAs was significant ( $p>0.1$ ), indicating that the three treatment groups were comparable in these demographic and clinical characteristics.

\section{Treatments}

Eligible mothers were assigned to one of three group programs designed to reduce distress and improve coping in relatives of people with schizophrenia: lecture-based (live) family psychoeducation, video-based family psychoeducation, or social skills training. Each program was provided weekly for four weeks, with sessions lasting 90 minutes, and five mothers per group. No further contact occurred between the group participants and each other or the clinician following completion of the group.

\section{Psychoeducation interventions}

The lecture-based psychoeducation program began each session with a 60-minute presentation with curriculum based on the Korean translation of Coping with Schizophrenia: A Guide for Families. ${ }^{25}$ The topics covered included: the prevalence and symptoms of schizophrenia; the principles of treatment (e.g., medication, stress management, social support, rehabilitation); understanding medication non-adherence; dealing with challenging situations such as medication non-adherence, bizarre or threatening behavior, suicidal thinking or behavior, severe negative symptoms, and substance abuse; and other issues related to client functioning, such as friendships, pregnancy, and work. A 30-minute question-and-answer period followed the lecture, in which mothers could ask questions specific to their own experiences, and share with each other effective strategies for handling common challenges. The video-based psychoeducation program included four videos that covered the same topics as the lectures, which were followed by a similar 30-minute question-and-answer period.

\section{Social skills training intervention}

The social skills training program was aimed at helping the mothers develop more effective interpersonal skills for coping with common challenging situations with their sons through the application of systematic skills training methods, ${ }^{20}$ including modeling (demonstrating) effective skills, engaging participants in role plays to practice skills, providing positive and corrective feedback after role plays to reinforce effort and good skills and make suggestions for improvements, additional role play practice, and mutually agreed upon home assignments for the mothers to practice their skills at home. Effective strategies for handling the following problem situations, based on the Coping with Schizophrenia book, ${ }^{25}$ were taught: violent behavior, medication non-adherence, bizarre or delusional speech, severe negative symptoms, suicidal behavior or ideation, and substance abuse.

The first social skills training group began with an introduction of the leader and group members, and a discussion of common challenging situations experienced by the mothers related to their sons with schizophrenia. Based on this discussion, a problem situation was identified to work on. The leader modeled the skill in one or more role plays, and then engaged each mother in several role plays to practice the skill. All role plays were followed by positive feedback and suggestions for improvement. At the end of the session a home assignment was developed for each mother to practice the skill on her own. The next group began with a review of the home assignment, selected role playing of mothers' experiences using the skill over the past week, discussion of the next problem area, and modeling and role playing of skills as in the first session, ending with the development of a home assignment.

\section{Measures}

At baseline, client's symptoms were evaluated with the Positive and Negative Syndrome Scale (PANSS), ${ }^{26}$ a widely used semi-structured interview for assessing the severity of psychiatric symptoms over the past week.

The Patient Rejection Scale, ${ }^{24}$ modified as previously described, was administered to the mothers at baseline to determine eligibility for the study, again one month later following the completion of each program, and then again 3-, 6-, and 9-months later. The Patient Rejection Scale has good internal reliability, with coefficient a's ranging between 0.71 and $0.83,{ }^{14,27-29}$ and good test-retest reliability, with Pearson correlations ranging between 0.72 and $0.92 .{ }^{14,30}$ In addition, the $\mathrm{Pa}$ tient Rejection Scale has demonstrated convergent validity cross culturally, with research conducted in the U.S., ${ }^{14}$ Germany, ${ }^{28,29}$ Israel, ${ }^{27}$ and India. ${ }^{30}$

At the baseline assessment of the present study, coefficient a for the Patient Rejection Scale was 0.56, at the post-treatment assessment it was 0.66 , at 3 -months post-treatment it was 0.58 , at 6 -months it was 0.68 , and at 9 -months post-treatment coefficient $a$ was 0.80 . The increase in coefficient $\alpha$ over the different assessments appears to reflect the fact that the study sample was initially selected based on uniformly high ratings on all items on the Patient Rejection Scale (participants score 3 or higher on all items), thereby constraining the range of possible scores and reducing the potential magnitude of the intercorrelations among items, or coefficient $\alpha$. In the absence of such imposed constraints, there was more variability in the 
ratings of different items, to the point where the coefficient $\alpha$ for the Patient Rejection Scale was greatest at the follow-up assessment with the greatest amount of variability on that scale. These coefficient a's suggest acceptable levels of internal reliability of the Patient Rejection Scale in this sample.

\section{Statistical analyses}

We evaluated differences between the three groups at baseline on participant age, years of education, marital status, and attitude on the Patient Rejection Scale, as well as the age of the son and total symptom severity on the PANSS, by performing one-way ANOVAs, with the three groups as the independent variable.

We used two approaches to evaluate the impact of the three caregiver interventions on changes in the Patient Rejection Scale from baseline to the post-treatment and 3-, 6-, and 9-month follow-up assessments. First, we performed mixed design ANOVAs across all assessments, ${ }^{31}$ with treatment group assignment as the independent variable. For these analyses, the group by time interaction is a test of whether the three groups differed over time in changes in the Patient Rejection Scale scores. Second, to compare the three treatment groups on the Patient Rejection Scale scores at each assessment following the baseline, we performed a series of one-way ANOVAs at the post-treatment, and 3-, 6-, and 9- month assessments. Significant group effects $(\mathrm{p}<0.05)$, indicating differences between the three groups, were followed up by conducting Tukey's Honestly Significantly Different (HSD) tests.

\section{RESULTS}

The ANOVAs comparing the three treatment groups at baseline on demographic, clinical, and attitude ratings indicated no significant differences between the groups.

Figure 1 shows the total scores on the Patient Rejection Scale at the five assessments. It can be seen that all three groups

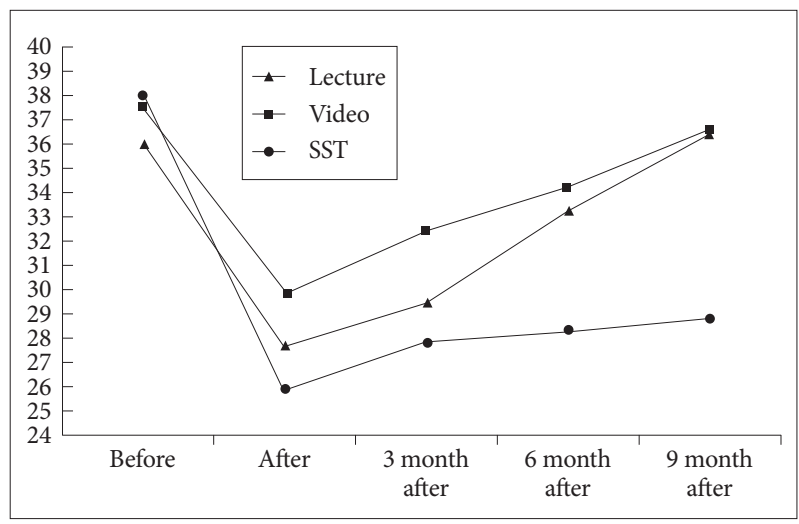

Figure 1. Changes in patient rejection scale overtime in the three groups. showed a reduction in the Patient Rejection Scale from baseline to the post-treatment assessment. However, the two psychoeducation groups gradually increased at the follow-up assessments, whereas the patient rejection ratings for the mothers in the social skills training group remained low.

The mixed design ANOVAs of changes in the Patient Rejection Scale indicated that the main effects for group, $\mathrm{F}(2$, $30)=0.509$, NS, and time $F(1,44)=1.155$, NS, were not statistically significant ( $\mathrm{ps}>0.10$ ). However, the group by time interaction was significant, $\mathrm{F}(2,44)=3.442, \mathrm{p}=0.041$, indicating significantly different changes over time between the three treatment groups. The ANOVA comparing the three groups at post-treatment indicated no significant differences, $\mathrm{F}(2$, $12)=2.173$, NS. The ANOVA for the 3-month assessment was significant, $\mathrm{F}(2,12)=4.238, \mathrm{p}=0.041$, as well as the ANOVAs for 6 months, $\mathrm{F}(2,12)=6.568, \mathrm{p}=0.012$ and 9 months, $\mathrm{F}(2,12)$ $=11.960, \mathrm{p}=0.001$. Tukey HSD tests indicated that at the 3 -month assessment mothers in the social skills training program had significantly $(\mathrm{p}<0.05)$ lower scores than on the $\mathrm{Pa}$ tient Rejection Scale than mothers in the video program, with mothers in the lecture program not significantly different from either group. For the 6-month and 9-month assessments, the Tukey HSD tests indicated that the mothers in the social skills program had significantly lower scores than those in the lecture or video program, which did not differ.

\section{DISCUSSION}

Mothers who participated in all of the different programs showed major reductions in their negative attitudes towards their sons immediately after completing either of the three treatment programs, with no differences between the live psychoeducation program, the video-based psychoeducation program, or the social skills training program. However, over the next nine months, the mothers in the two psychoeducational programs showed gradual increases in their rejecting attitudes towards their sons, whereas the mothers in the social skills training program did not, with the difference between the groups statistically significant at each follow-up point. Thus, social skills training was more effective than psychoeducation at producing sustained reductions in the negative attitudes of mothers towards a son with schizophrenia.

All three programs were associated with a dramatic reduction in the negative attitudes of the mothers towards their sons. The message of hope contained in the two psychoeducational interventions, combined with social support from the other mothers in the group, may have contributed to these immediate reductions in rejecting attitudes among these participants. ${ }^{10,32}$ However, social support from other mothers was available to the study participants for only a limited period of 
time (i.e., a four-week period). It is possible that lack of access to long-term social support over time (e.g., multiple family support groups), in the absence of training more effective and long-lasting interpersonal skills for dealing with challenging situations involving their sons, may have contributed to the waning of beneficial effects on negative attitudes for mothers in the two psychoeducational interventions.

In contrast to the psychoeducation programs, the skills training program had more enduring effects on reducing the mothers' rejecting attitudes towards their son. Social skills training is aimed at teaching individuals more effective interpersonal skills through the systematic application of the principles of social learning theory: modeling, repeated behavioral rehearsal, reinforcement to shape behaviors, homework to generalize newly learned behaviors to real life situations. ${ }^{20}$ Thus, skills training may have enabled these mothers to develop more effective interpersonal coping strategies for dealing with challenging situations, which they were able to use on their own after the program had ended. These findings suggest that short-term programs aimed at improving coping skills and negative attitudes of family members towards a member with severe mental illness would benefit from the inclusion of skills training aimed at teaching more effective interpersonal behaviors, and should avoid a narrow focus on providing psychoeducation.

Several limitations of this pilot study should be noted. First, the sample size was small, and therefore the findings are in need of replication with a larger number of participants. Second, mothers were not randomized to the different programs. Although the groups did not differ at baseline on any measures, there is a need to more rigorously evaluate the effects of the social skills training program in a randomized controlled trial. Third, the study focused only on mothers and sons, suggesting the need to extend the research to fathers and other family members who may play a caregiving role to relatives with schizophrenia, as well as daughters with schizophrenia. These limitations notwithstanding, this study suggests that time-limited social skills training may have an important role to play in helping distressed caregiving relatives cope more effectively with challenging behaviors in an offspring with schizophrenia, and that more research is warranted on this approach.

\section{REFERENCES}

1. Baronet AM. Factors associated with caregiver burden in mental illness: a critical review of the research literature. Clin Psychol Rev 1999;19: 819-841.

2. Perlick DA, Rosenheck RA, Kaczynski R, Swartz MS, Cañive JM, Lieberman JA. Components and correlates of family burden in schizophrenia. Psychiatr Serv 2006;57:1117-1125.

3. Bulger MW, Wandersman A, Goldman CR. Burdens and gratifications of caregiving: appraisal of parental care of adults with schizophrenia. Am J Orthopsychiatry 1993;63:255-265.

4. Hooley JM. Expressed emotion and relapse of psychopathology. Annu Rev Clin Psychol 2007;3:329-352.

5. Mueser KT, Webb C, Pfeiffer M, Gladis M, Levinson DF. Family burden of schizophrenia and bipolar disorder: perceptions of relatives and professionals. Psychiatr Serv 1996;47:507-511.

6. Schene AH, van Wijngaarden B, Koeter MW. Family caregiving in schizophrenia: domains and distress. Schizophr Bull 1998;24:609-618.

7. Lefley H. Family Psychoeducation in Serious Mental Illness: Models, Outcomes, Applications. New York: Oxford University Press; 2009.

8. Leff J, Berkowitz R, Shavit N, Strachan A, Glass I, Vaughn C. A trial of family therapy v. a relatives group for schizophrenia. Br J Psychiatry 1989;154:58-66.

9. McFarlane WR, Lukens E, Link B, Dushay R, Deakins SA, Newmark M, et al. Multiple-family groups and psychoeducation in the treatment of schizophrenia. Arch Gen Psychiatry 1995;52:679-687.

10. Pickett-Schenk SA, Cook JA, Steigman P, Lippincott R, Bennett C, Grey DD. Psychological well-being and relationship outcomes in a randomized study of family-led education. Arch Gen Psychiatry 2006;63:10431050.

11. McFarlane WR, Link B, Dushay R, Marchal J, Crilly J. Psychoeducational multiple family groups: four-year relapse outcome in schizophrenia. Fam Process 1995;34:127-144.

12. Dyck DG, Short RA, Hendryx MS, Norell D, Myers M, Patterson T, et al. Management of negative symptoms among patients with schizophrenia attending multiple-family groups. Psychiatr Serv 2000;51:513-519.

13. Falloon IR, Pederson J. Family management in the prevention of morbidity of schizophrenia: the adjustment of the family unit. Br J Psychiatry 1985;147:156-163.

14. Schooler NR, Keith SJ, Severe JB, Matthews SM, Bellack AS, Glick ID, et al. Relapse and rehospitalization during maintenance treatment of schizophrenia. The effects of dose reduction and family treatment. Arch Gen Psychiatry 1997;54:453-463.

15. Tarrier N, Barrowclough C, Vaughn C, Bamrah JS, Porceddu K, Watts S, et al. Community management of schizophrenia. A two-year follow-up of a behavioural intervention with families. Br J Psychiatry 1989;154: 625-628.

16. Leavey G, Gulamhussein S, Papadopoulos C, Johnson-Sabine E, Blizard B, King M. A randomized controlled trial of a brief intervention for families of patients with a first episode of psychosis. Psychol Med 2004; 34:423-431.

17. Solomon P, Draine J, Mannion E, Meisel M. Effectiveness of two models of brief family education: retention of gains by family members of adults with serious mental illness. Am J Orthopsychiatry 1997;67:177-186.

18. Vaughan K, Doyle M, McConaghy N, Blaszczynski A, Fox A, Tarrier N. The Sydney intervention trial: a controlled trial of relatives' counselling to reduce schizophrenic relapse. Soc Psychiatry Psychiatr Epidemiol 1992;27:16-21.

19. Solomon P, Draine J, Mannion E, Meisel M. Impact of brief family psychoeducation on self-efficacy. Schizophr Bull 1996;22:41-50.

20. Bellack AS, Mueser KT, Gingerich S, Agresta J. Social Skills Training for Schizophrenia: a Step-by-Step Guide (Second ed). New York: Guilford Press; 2004.

21. Liberman RP, DeRisi WJ, Mueser KT. Social Skills Training for Psychiatric Patients. Needham Heights, MA: Allyn \& Bacon; 1989.

22. Dixon L, Adams C, Lucksted A. Update on family psychoeducation for schizophrenia. Schizophr Bull 2000;26:5-20.

23. Pitschel-Walz G, Bäuml J, Bender W, Engel RR, Wagner M, Kissling W. Psychoeducation and compliance in the treatment of schizophrenia: results of the Munich Psychosis Information Project Study. J Clin Psychiatry 2006;67:443-452.

24. Kreisman DE, Simmens SJ, Joy VD. Rejecting the patient: preliminary validation of a self-report scale. Schizophr Bull 1979;5:220-222.

25. Mueser KT, Gingerich SL. Coping with Schizophrenia: a Guide for 
Families. Oakland, CA: New Harbinger; 1994.

26. Kay SR, Fiszbein A, Opler LA. The positive and negative syndrome scale (PANSS) for schizophrenia. Schizophr Bull 1987;13:261-276.

27. Heresco-Levy U, Brom D, Greenberg D. The Patient Rejection Scale in an Israeli sample: correlations with relapse and physician's assessment. Schizophr Res 1992;8:81-87.

28. Bailer J, Rist F, Bräuer W, Rey ER. Patient Rejection Scale: correlations with symptoms, social disability and number of rehospitalizations. Eur Arch Psychiatry Clin Neurosci 1994;244:45-48.

29. Watzl H, Rist F, Cohen R. The patient rejection scale: cross-cultural con- sistency. Schizophr Bull 1986;12:236-238.

30. Manickam LS, Chandran SR. Rejection of chronic schizophrenic patients: some preliminary observations from kerala. Indian J Psychiatry 1998;40:274-279.

31. Fitzmaurice G, Laird N, Ware J. Applied Longitudinal Analysis. New York: John Wiley \& Sons; 2004.

32. Dixon L, Lucksted A, Stewart B, Burland J, Brown CH, Postrado L, et al. Outcomes of the peer-taught 12 -week family-to-family education program for severe mental illness. Acta Psychiatr Scand 2004;109:207-215. 